\title{
In search of traceability: two decades of calibrated Brewer UV measurements in Sodankylä and Jokioinen
}

\author{
Anu Heikkilä ${ }^{1}$, Jakke Sakari Mäkelä ${ }^{1, a}$, Kaisa Lakkala ${ }^{2}$, Outi Meinander ${ }^{1}$, Jussi Kaurola ${ }^{1}$, Tapani Koskela ${ }^{3}$, \\ Juha Matti Karhu ${ }^{2}$, Tomi Karppinen ${ }^{2}$, Esko Kyrö ${ }^{2}$, and Gerrit de Leeuw ${ }^{1,4}$ \\ ${ }^{1}$ Finnish Meteorological Institute, Climate Research, P.O. Box 503, 00101 Helsinki, Finland \\ ${ }^{2}$ Finnish Meteorological Institute, Arctic Research Center, Tähteläntie 62, 99600 Sodankylä, Finland \\ ${ }^{3}$ independent researcher: Helsinki, Finland \\ ${ }^{4}$ University of Helsinki, Department of Physics, P.O. Box 64, 00014 University of Helsinki, Helsinki, Finland \\ ${ }^{\mathrm{a}}$ currently at: University of Jyväskylä, Jyväskylä, Finland \\ Correspondence to: Anu Heikkilä (anu.heikkila@fmi.fi)
}

Received: 7 December 2015 - Published in Geosci. Instrum. Method. Data Syst. Discuss.: 18 January 2016

Revised: 15 October 2016 - Accepted: 25 October 2016 - Published: 22 November 2016

\begin{abstract}
The two Brewer spectrophotometers of the Finnish Meteorological Institute at Jokioinen and Sodankylä have been operated according to the highest levels of the WMO/GAW (World Meteorological Organization/Global Atmosphere Watch) recommendations with rigorous quality control and quality assurance. The calibration of the instruments is based on annual recalibrations of primary standard lamps in the VTT MIKES Metrology National Standards Laboratory in Finland and an exhaustive measurement program with measurements of standard and working lamps in the on-site optical laboratories. Over the years, the maintenance of the calibration has produced data sets of approximately 2000 lamp scans for both instruments. An extensive re-examination of the lamp measurements and the response of the spectrophotometers was carried out. The primary standard lamps were found to age on an average rate of $0.3 \%$ per burn. The responsivity at wavelength $311 \mathrm{~nm}$ was found to exhibit both long-term and short-term changes. The overall long-term change was declining. In addition, abrupt changes of as large as $25 \%$ were detected. The short-term changes were found to fluctuate on time frames shorter than the interval between the measurements of the primary standard lamps. This underlines the importance of the use of more frequently measured working standard lamps.
\end{abstract}

\section{Introduction}

The Brewer spectrophotometers are used to measure total atmospheric column ozone and spectral irradiance at the UV part of the solar spectrum. The absolute calibration of a spectrophotometer is a crucial part of the measurement chain needed to obtain solar UV spectra with the lowest achievable uncertainty. In fact, maintenance of reliable absolute calibration may be considered as the most important requirement in UV spectroradiometry (Garane et al., 2006). The calibration is a challenging task due to several reasons: it has to be considered that the instrument measures each of the solar irradiance wavelengths separately, the signals at short wavelengths are orders of magnitude smaller than at longer wavelengths, the uncertainties differ at different wavelengths, the calibration lamps themselves are ageing and as a result their spectral output is changing whenever they are used, and multiple transfer standards need to be used.

Estimations on the uncertainties in measurements of solar UV(-B) irradiance range from 5 to $10 \%$ (Gardiner, 1997). The dominating source of uncertainty is attributable to uncertainties in the calibration standards (Eleftheratos et al., 2014). Intercomparisons of the irradiance scales disseminated by the different National Metrology Institutes (NMIs) have varied from 2 to $5 \%$ (Walker et al., 1991; Webb et al., 2003). While the uncertainties of the scales provided by NMIs are expected to decrease, as the institutes re-establish their scales by linking them to primary detector scales, the uncertainties related 
to the performance of transfer standard lamps and the calibration set-up remain the key components in the overall uncertainty.

Guidelines for quality control and quality assurance for solar UV irradiance measurements have been prepared under the auspices of WMO/GAW (World Meteorological Organization/Global Atmosphere Watch) (Webb et al., 1998, 2003; Seckmeyer et al., 2001). The guidelines set the general requirements that have to be met when pursuing data of high quality. They recommend, for instance, that multiple lamps be used in each calibration event, that stability checks on the responsivity be done at least monthly, that recalibration of the reference and working standard lamps be performed annually, and that working standard lamp be not more than two steps apart from the National Standards Laboratory. The generality of the guidelines ensures their wide applicability. Many choices are necessarily left up to the discretion of the operator: on which lamps to base the determination of the responsivity of the instrument, how small changes should trigger an update in the responsivity, and how exactly the daily response time series is to be derived.

A review of the literature shows that the methods and algorithms differ amongst the stations maintaining spectrophotometers for measurements of solar spectral UV irradiance (Lam et al., 2002; Kazadzis et al., 2005; Garane et al., 2006, Lakkala et al., 2008; Simic et al., 2008; Schneider et al., 2008; Ialongo et al., 2008; Sabburg et al., 2001; Damiani et al., 2012). The measurements with Brewer \#037 and Brewer \#107 spectrophotometers at Sodankylä and Jokioinen respectively have followed the WMO recommendations, with stability checks every 3-4 weeks and measurements of standard lamps in laboratory (darkroom) every 6-8 weeks. In this study, the lamp measurements collected over the operational years of the spectrophotometers are looked into to examine the changes in the lamps and in the responsivities of the instruments. In addition to the long-term changes, the short-term variations and abrupt changes are of interest. Furthermore, the method adopted in the determination of the responsivity of the instrument is presented. Both the Level 1 responsivity used for online near real-time processing and the Level 2 responsivity used for offline post-processing of solar UV irradiance spectra are dealt with.

\section{Brewer spectrophotometer and its calibration for solar spectral UV irradiance measurements}

The Brewer spectrophotometer (Brewer, 1973; Bais et al., 1996) is a widely used instrument to monitor solar UV radiation. The instrument is used to collect photons of the incoming radiation through the entrance optics, separate the incoming photons according to their wavelength by a monochromator, and record the amount of photons at each wavelength. The Finnish Meteorological Institute has operated Brewer spectrophotometers at two meteorological sounding stations, one in Sodankylä $\left(67.37^{\circ} \mathrm{N}, 27.63^{\circ} \mathrm{E}\right)$ since 1990 and the other in Jokioinen $\left(60.81^{\circ} \mathrm{N}, 23.50^{\circ} \mathrm{E}\right)$ since 1995 . Brewer \#037 located in Sodankylä is a model MkII with a single monochromator and a wavelength range from 290 to $325 \mathrm{~nm}$. Brewer \#107 operated in Jokioinen is of type MkIII using a double monochromator, consisting of two consecutive monochromators along the path of the photons. The wavelength range of Brewer \#107 extends from 286.5 to $365 \mathrm{~nm}$. In November 2015, Brewer \#107 was moved to Helsinki $\left(60.20^{\circ} \mathrm{N}, 24.96^{\circ} \mathrm{E}\right)$ where it has been operated ever since.

The solar UV photons collected by a spectrophotometer are converted into the principal measurand spectral irradiance, in units $\mathrm{W} \mathrm{m}^{-2} \mathrm{~nm}^{-1}$. Several products are further computed from the spectral irradiance (Mäkelä et al., 2016). The conversion from photon counts into spectral irradiance is done using a response-related conversion function that has been determined by measuring a source of UV radiation, i.e. a lamp, with known (certified) spectral irradiance. By this procedure, the measurements of the spectrometer become fixed onto a certain level of irradiance, i.e. calibrated. Regular and frequent enough lamp measurements are also needed to monitor the stability of the responsivity of the spectrophotometer.

The calibration of the Brewer spectrophotometers \#037 and \#107 is based on primary (reference) standard lamps regularly recalibrated in the National Standards Laboratory at VTT MIKES Metrology (hereinafter denoted as NSL) and regular lamp measurements in the on-site optical laboratories in Sodankylä and Jokioinen. Measurements of $1000 \mathrm{~W}$ standard lamps are used as a basis for the determination of the responsivity of the instruments. In addition to the primary standard lamps recalibrated regularly by NSL, several secondary and working standard lamps are used. The irradiance scale is transferred from the primary standard lamps to the secondary and working standard lamps to avoid unnecessary burning and consequent premature ageing of the primary standards. Secondary standard lamps are used to preserve the calibration provided by primary lamps and are therefore burned sparingly. Working standard lamps are used most frequently in the on-site laboratory measurements.

A portable lamp unit with $50 \mathrm{~W}$ lamps has been used both outdoors for stability checks and in laboratory for ancillary measurements. The outdoor lamp measurements are done in the evening, preferably after sunset. In case the measurements have to be made before sunset, separate solar UV scans are taken in between the lamp scans to ensure adequate sampling of the accumulating daily UV dose. The frequent measurements of the $50 \mathrm{~W}$ lamps are useful for detection of occasional sudden changes in the response of the instruments.

\section{Lamp measurements in on-site darkrooms}

The first lamp measurements with a portable calibrator and $50 \mathrm{~W}$ lamps were performed in June 1990 in Sodankylä and 
in January 1997 in Jokioinen. The on-site optical laboratories were built in 1997, and the first scans of $1000 \mathrm{~W}$ lamps in the darkroom were made in June and October 1997 in Jokioinen and Sodankylä respectively. Until the end of 2015, the lamp measurements extending over 25 years for Brewer \#037 has resulted in 1931 lamp scans on 325 days. For Brewer \#107, a data set of 2012 lamp scans on 553 days has accumulated. The procedure used for the scanning of the lamps has slightly changed over the years. In Sodankylä, two different ways have been used as follows:

a. 6 June 1990-4 December 1997: upward-downward scan with $35 \AA$ step

b. 5 December 1997-present: upward scan with $5 \AA$ A step

In Jokioinen, three different ways have been used:

a. 7 January 1997-10 January 1997: upward scan 2900$3630 \AA$, step $10 \AA$

b. 22 January 1997-25 June 1997: upward scan 2865$3630 \AA$, step $5 \AA$

c. 26 June 1997-present: upward scan 2865-3650 А, step $5 \AA$

Figure 1 shows examples of dark count corrected raw counts produced and printed out into files named XLjjjyy.107 and ULjjjyy.037 (jjj denoting the Julian date, yy denoting the year) for lamp scans performed by Brewer \#107 and Brewer \#037 respectively in units counts cycle ${ }^{-1}$. The photons entering the spectrometer are selectively passed onto the detector, the cathode of the photomultiplier tube. During the scan, the dispersing grating(s) are rotated by step motors to pass on photons with nominally only one wavelength at a time. Six separate exit slits are positioned after the (first) grating. A slotted rotating slit mask is used, driven by another step motor, to expose only one or two of the slits at a time, or to prevent radiation from entering any of the slits, to enable measurement of the dark counts. In Brewer \#037, the slit mask is positioned at the exit slit of the monochromator. In Brewer \#107, the slit mask is positioned at the entrance of the second (recombining) monochromator. The slit mask cycles back and forth between optical end stops.

In external lamp scans of Brewer \#107, the slit mask is cycled through 30 oscillations for wavelengths shorter than $300 \mathrm{~nm}$ and through 20 oscillations for wavelengths longer than $300 \mathrm{~nm}$. More cycles are used at the lower wavelengths to ensure acceptable statistics, i.e. collection of photons for acceptable signal-to-noise ratio. The photon counts $F_{i}$ are accumulated through slit \#1 for wavelengths shorter than $350 \mathrm{~nm}$ and through slit \#5 for wavelengths longer than $350 \mathrm{~nm}$. This can be seen as a jump in the curve of the raw counts of Brewer \#107 in Fig. 1. In addition, the dark counts $F_{1}$ from one of the slit mask positions is recorded. Brewer \#037 uses 30 cycles over its whole wavelength range (290$325 \mathrm{~nm}$ ). In Brewer \#107, the dark current corrected photon

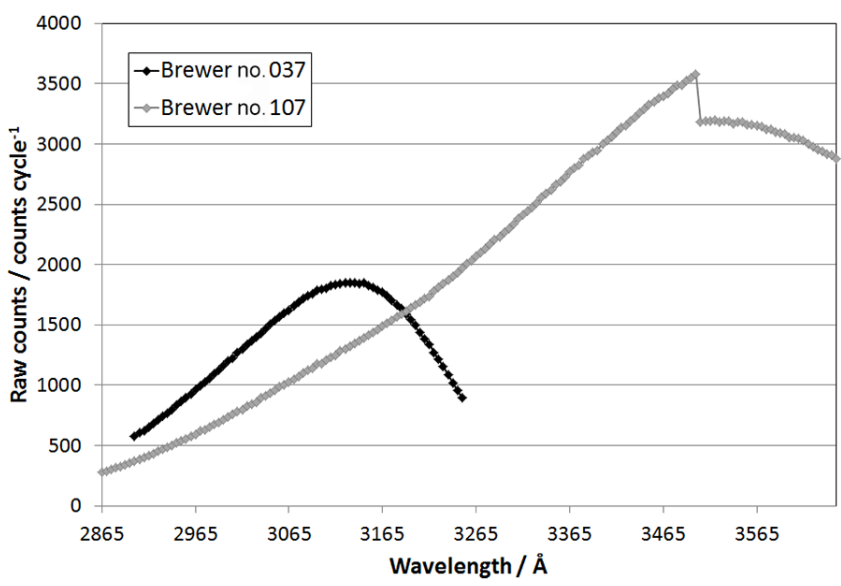

Figure 1. Typical spectral irradiance measurements of a $1000 \mathrm{~W}$ standard lamp as raw counts per cycle. Brewer \#037 measurement taken with primary standard lamp D24 on 20 March 2012. Brewer \#107 measurement taken with primary standard lamp D01 on 26 January 2012.

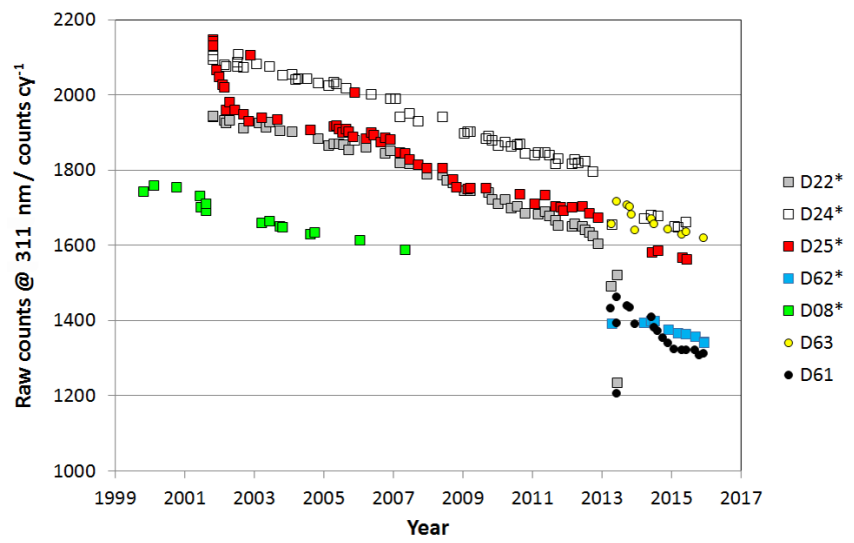

Figure 2. Time series of the raw counts (in units counts per cycle) at $311 \mathrm{~nm}$ recorded by Brewer \#037 spectrophotometer in measurements of a selection of $1000 \mathrm{~W}$ lamps. The lamps marked with an asterisk are primary standard lamps regularly recalibrated in VTT MIKES Metrology.

counts $\left(F_{i}-F_{1}\right)$ are output (in XLjjjyy.107) as normalized to one-cycle observations. In Brewer \#037, they are output (in on the basis of the lamps D14ULjjjyy.037) as such, accumulated over the total of 30 cycles. In Fig. 1, the raw count readings for Brewer \#037 have been divided by 30, i.e. normalized to one measurement cycle.

The time series of the raw counts may be examined as such to examine the temporal development of the responsivity of the instrument. Figures 2 and 3 show plots of raw counts at $311 \mathrm{~nm}$ extracted from the measurements of a selection of $1000 \mathrm{~W}$ lamps. The wavelength of $311 \mathrm{~nm}$ was chosen to be used throughout this study since this wavelength was also measured in the earlier scans in the 1990s. The effects of the changes in the instrument's response and the ageing of 


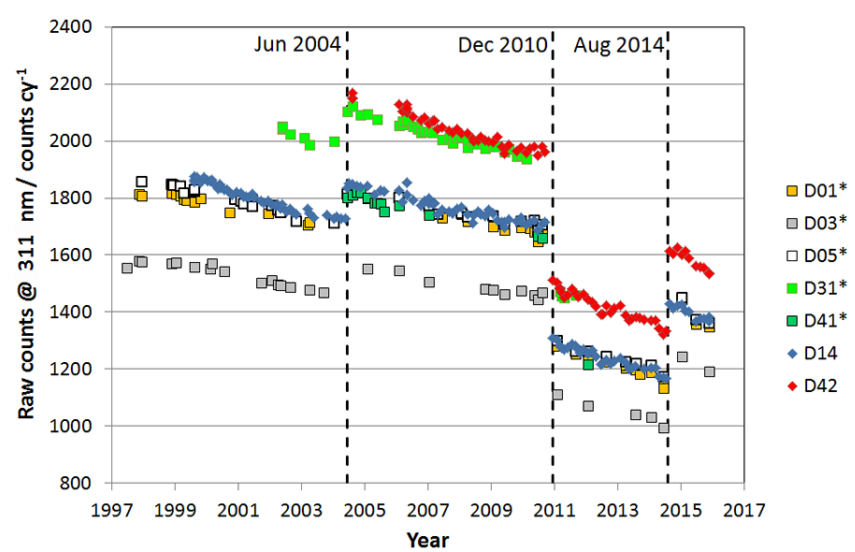

Figure 3. Time series of the raw counts (in units counts per cycle) at $311 \mathrm{~nm}$ recorded by Brewer \#107 spectrophotometer in measurements of a selection of $1000 \mathrm{~W}$ lamps. The lamps marked with an asterisk are primary standard lamps regularly recalibrated in VTT MIKES Metrology.

the lamp are superimposed in the recorded counts per cycle. However, the figures may provide some preliminary information on the changes in responsivity, since the counts recorded from all the lamps follow the same pattern, no matter how frequently they are burned. It therefore appears that the ageing of the lamp has a notably smaller effect than the longterm change in the instrument's responsivity. There is a general downward tendency in the response of both instruments. In Brewer \#107, three abrupt changes in the responsivity are obvious: the first in June 2004, the second in January 2010, and the third in August 2014. Short-term changes may also be seen in raw lamp counts of Brewer \#037, although on a smaller scale.

\section{Calibration of primary standard lamps}

The calibration of the Brewer spectrophotometers is based on an irradiance scale that was transferred to the on-site optical laboratories by primary standard lamps. Over the years 1990-1998, four different laboratories were used as suppliers of calibration of the primary standard lamps: GigahertzOptik GmbH (GH), Germany; Optronics Laboratories Inc. (OL), US; Radiation and Nuclear Safety Authority in Finland (STUK); and Statens Provningsanstalt (SP), Sweden. The years 1999-2001 denoted a period of transition during which the calibrations were ordered from SP, STUK, GH, and VTT MIKES Metrology (formerly: MIKES Helsinki University of Technology HUT), which includes the National Standards Laboratory (NSL) in Finland. Since December 2001, the calibrations have been ordered solely from NSL.

The comparison measurements of spectral irradiance scales organized by the Consultative Committee for Photometry and Radiometry (CCPR) in 1990, 1996, and 2005 have shown differences between the irradiance scales provided by

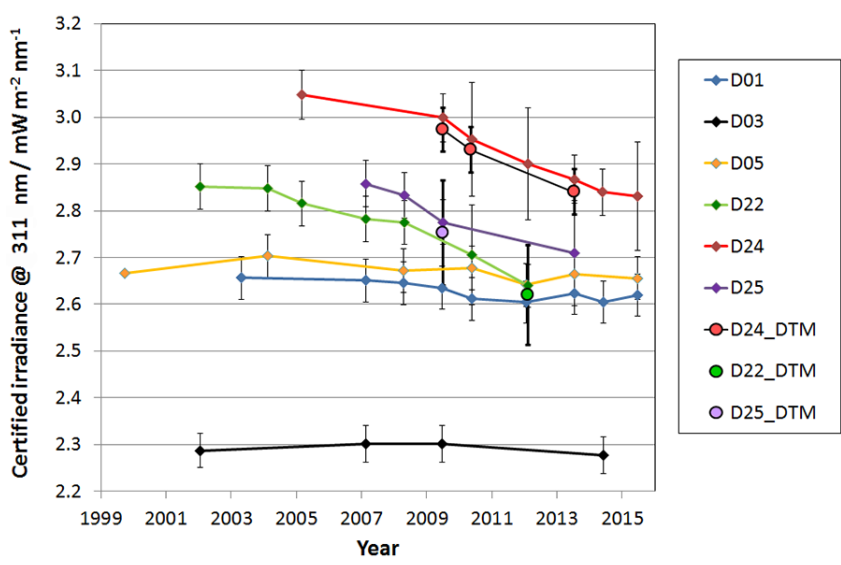

Figure 4. Irradiance at $311 \mathrm{~nm}$, as certified by the NSL, of the primary standard lamps used in calibration of Brewer \#037 in Sodankylä (D22, D24, and D25) and Brewer \#107 in Jokioinen (D01, D03, and D05). The filled circles denote parallel calibrations performed using Bentham DTMc300, extending over wavelengths $250-2100$ or $250-2500 \mathrm{~nm}$, traceable to another irradiance scale.

different laboratories. Walker et al. (1991) reported differences of 2-4\% in the 1990 intercomparison in the UV wavelengths. A spread of $\pm 5 \%$ at wavelength $300 \mathrm{~nm}$ was obtained in the 1996 intercomparison (Webb et al., 2003). Concentrating the recalibrations of the primary standard lamps of Brewer \#037 and \#107 exclusively into NSL has removed the uncertainty related to the differences in the irradiance scales.

The primary standard lamps are $1 \mathrm{~kW}$ tungsten-filament incandescent halogen lamps of type DXW operated in vertical orientation in a distance of $50 \mathrm{~cm}$ of the focal plane of the diffuser. The calibration of the primary standard lamps at NSL is carried out by using the method for the realization of the detector-based spectral irradiance scale (Kübarsepp et al., 2000). The absolute responsivity of the used trap detector is traceable to the cryogenic electrical substitution radiometer of Statens Provningsanstalt, Sweden. In the 1990s, lamps manufactured by GH and OL were used. Currently, all the primary standard lamps regularly used in Jokioinen and Sodankylä are manufactured by GH. The lamps are labelled by a running number preceded by the letter " $\mathrm{D}$ ". Information on the lamps currently in use is compiled in Table 1.

Figure 4 shows the temporal development of the radiative output of the lamps at one selected wavelength, $311 \mathrm{~nm}$, for six primary standard lamps currently in use in Jokioinen and Sodankylä. Lamps D01, D03, and D05 seem to have stayed within the calibration uncertainty throughout the time of their use. Lamps D22, D24, and D25, on the contrary, seem to have lost some of their intensity. In Sodankylä, however, the primary standard lamps are scanned more frequently in the on-site darkroom than in Jokioinen. The primary lamps have been measured in the on-site laboratories 1-3 times per year in Jokioinen and 2-4 times per year in Sodankylä. The lamp may be expected to age in some extent every time the lamp 
Table 1. Information on the primary standard lamps used in calibration of Brewer \#037 and \#107.

\begin{tabular}{llllrr}
\hline Lamp & Primary to & 1st calibration & Last calibration & $\begin{array}{r}\text { Number of } \\
\text { (re)calibrations }\end{array}$ & $\begin{array}{r}\text { Scans at home } \\
\text { laboratory }\end{array}$ \\
\hline D01 & Brewer \#107 & 26.03 .2003 & 19.05 .2015 & 9 & 44 \\
D03 & Brewer \#107 & 14.12 .2001 & 29.04 .2014 & 4 & 42 \\
D05 & Brewer \#107 & 20.08 .1999 & 19.05 .2015 & 7 & 44 \\
D31 & Brewer \#107 & 26.03 .2003 & 31.01 .2005 & 2 & 46 \\
D41 & Brewer \#107 & 20.04 .2010 & 21.12 .2011 & 2 & 16 \\
D24 & Brewer \#037 & 03.02 .2005 & 21.05 .2015 & 10 & 59 \\
D22 & Brewer \#037 & 14.12 .2001 & 06.01 .2012 & 8 & 51 \\
D25 & Brewer \#037 & 14.01 .2007 & 14.06 .2013 & 5 & 56 \\
D62 & Brewer \#037 & 14.06 .2013 & 21.05 .2015 & 4 & 10 \\
D08 & Brewer \#037 & 11.01 .2004 & 11.01 .2004 & 1 & 18 \\
\hline
\end{tabular}

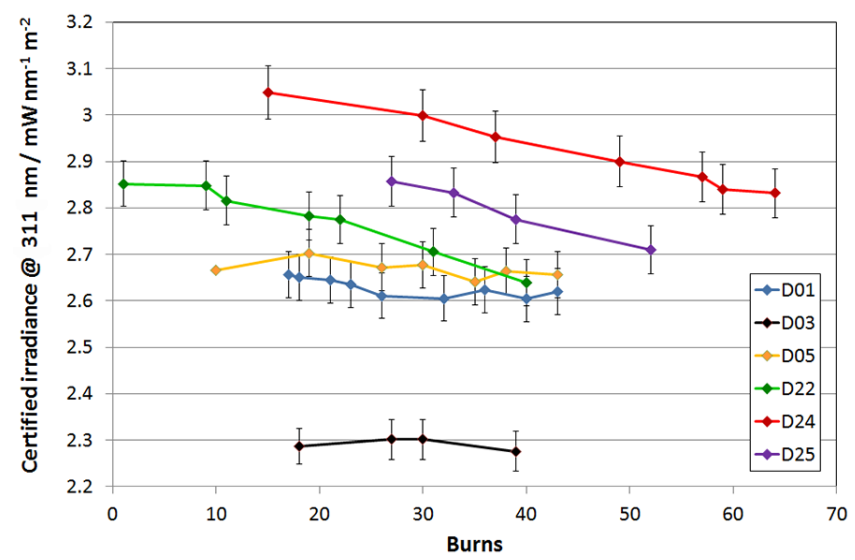

Figure 5. Ageing rate of the primary standard lamps used in calibration of Brewer \#037 in Sodankylä and Brewer \#107 in Jokioinen, given by the NSL-certified irradiance at $311 \mathrm{~nm}$ as a function of the number of burning events.

is burned. Examination on the certified irradiances at $311 \mathrm{~nm}$ reveals overall drifts ranging from $-0.4 \%$ (D05) to $-7.6 \%$ (D22), translating into annual drifts ranging from -0.03 to $-0.81 \%$. Figure 5 shows the certified irradiances at $311 \mathrm{~nm}$ as functions of the number of the burning events. The primary standard lamps appear to age $0.05-0.6 \%$ per burn, depending on the lamp, with the average ageing rate being approx. $0.3 \%$ per burn.

The filled circles in Fig. 4 denote parallel calibrations performed using a Bentham DTMc300 spectroradiometer, extending over wavelengths $250-2100$ or $250-2500 \mathrm{~nm}$. The scale is traceable to MRI (Metrology Research Institute, Finland) for wavelengths below $900 \mathrm{~nm}$, and to NPL (National Physical Laboratory, UK) for wavelengths above $900 \mathrm{~nm}$. These certificates are not used for the calibration of Brewer spectrophotometers, but for other radiometers with a wavelength range extending to the infrared. However, they illustrate a difference between two irradiance scales. The difference is less than $1 \%$ at $311 \mathrm{~nm}$.

\section{Determination of responsivity}

The instrument-specific spectral responsivity is needed to translate the raw photon counts recorded by the spectrometer in spectral irradiance. The formula connecting the irradiance $E(\lambda)$ (in units $\mathrm{W} \mathrm{m}^{-2} \mathrm{~nm}^{-1}$ ), the count rate $C(\lambda)$ (in counts $\mathrm{s}^{-1}$ ), and the responsivity $R(\lambda)$ (in units counts $\left.\mathrm{s}^{-1} \mathrm{~W}^{-1} \mathrm{~m}^{2} \mathrm{~nm}\right)$ is

$E(\lambda)=C(\lambda) / R(\lambda)$.

The responsivity may be hence derived by dividing the count rate obtained in a measurement of a radiation source with known (certified) irradiance. For the Brewer spectrophotometers, this means a primary standard lamp calibrated by NSL or a secondary standard or a working standard lamp where the scale provided by NSL has been transferred. The count rate is derived from the dark-current-corrected raw counts $\left(F_{i}-F_{1}\right)$. The photomultiplier tube has a prescaler that divides the photon pulses by 4 . The actual counts (number of photons) recorded are therefore $4 \cdot\left(F_{i}-F_{1}\right)$. The time taken by CY slit mask cycles back and forth is $2 \cdot \mathrm{CY} \cdot \mathrm{IT}$, with $\mathrm{CY}$ denoting the number of cycles and IT denoting the integration time predefined as $0.1146 \mathrm{~s}$. Hence, the count rate (in units counts $\mathrm{s}^{-1}$ ) is derived for each wavelength $i$ using the formula

$C_{i}=\frac{4 \cdot\left(F_{i}-F_{1}\right)}{2 \cdot \mathrm{CY} \cdot \mathrm{IT}}=\frac{2 \cdot\left(F_{i}-F_{1}\right)}{\mathrm{CY} \cdot \mathrm{IT}}$.

The count rate is further corrected by the processing software for the dead time of the photomultiplier tube and for the stray light. A detailed description of the processing is given in Mäkelä et al. (2016).

\subsection{Level 1 responsivity for near real-time processing}

The responsivity of the spectrophotometer is determined for the day the (primary standard) lamp is measured in the onsite laboratory. Usually, at least three different $1000 \mathrm{~W}$ standard lamps are measured during the same day. After a recal- 


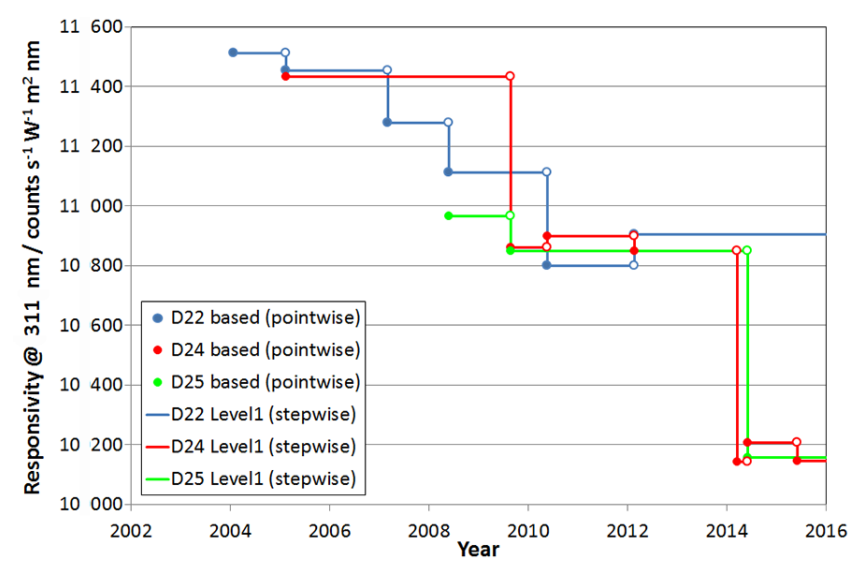

Figure 6. Responsivity of Brewer \#037 as determined on the basis of the newly recalibrated primary standard lamps D22, D24, and D25 (discrete values) and the corresponding stepwise constant responsivity of type Level 1 used for near real-time processing of solar UV irradiance spectra.

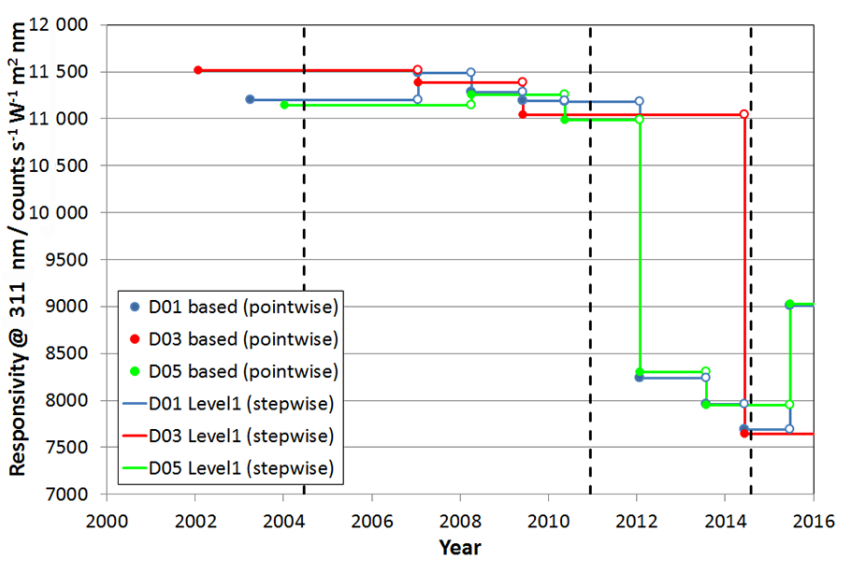

Figure 7. Responsivity of Brewer \#107 as determined on the basis of the newly recalibrated primary standard lamps D01, D03, and D05 (discrete values) and the corresponding stepwise constant responsivity of type Level 1 used for near real-time processing of solar UV irradiance spectra.

ibration of the primary standard lamps in NSL, several secondary and working standard lamps are measured in a row during a laboratory session of 1-2 days to transfer the irradiance scale from the newly recalibrated primary standard lamps to the secondary and working standard lamps. The responsivity may be based on one single lamp or on an average of two to three trusted lamps. The obtained responsivity is assumed to stay constant until the next scan of a standard lamp indicating a change in the responsivity of the instrument.

Figures 6 and 7 show the responsivity of Brewer \#037 and \#107 determined on the basis of measurements of three primary standard lamps in the on-site laboratories immediately after the recalibrations of the lamps in NSL. From the discrete points of the determined responsivity, the stepwise constant (Level 1) responsivity time series are formed. These kinds of responsivities are used in the near real-time processing of the solar UV measurements made by Brewer spectrophotometers \#037 and \#107. The operator may choose to fix the responsivity onto one lamp only or use an average of two to three lamps.

The stepwise Level 1 responsivity shown by Figs. 6 and 7 give insight into the true changes in the responses of the instruments, cleaned of the effect of the ageing of the lamps. The responsivity of Brewer \#037 seems to decline fairly steadily. The largest drop of the order of $-5 \%$ is detected in the measurements of lamps D24 and D25 since the beginning of 2014. The abrupt changes obvious in the raw counts (Fig. 3) are also seen in the responsivity of Brewer \#107. During 2002-2012, the responsivity at $311 \mathrm{~nm}$ declined by approx. $4 \%$. The largest drop in the responsivity was seen in the beginning of 2012. The change was approx. $-25 \%$. It is noteworthy that the change already took place in December 2010. In case no measurements of working standard lamps had been taken between the relatively sparse measurements of primary standard lamps, the Level 1 responsivity used for the near real-time processing of solar UV irradiance spectra would have remained on a faulty level for more than 12 months.

\subsection{Level 2 responsivity for post-processing}

In addition to the near real-time processing of solar UV irradiance measurements made by Brewer \#037 and \#107 spectrophotometers producing Level 1 data, the scans are retrospectively post-processed to produce Level 2 data. This allows the operator to account for even the small scale variations in responsivity that were neglected in the near real-time processing. In addition, it allows the operator to retrospectively view the behaviour of each individual lamp, separate the true changes in the instrument from the changes in the lamp, and choose the trusted lamps to serve as the basis of the determination of the responsivity for each period of time.

To demonstrate the determination of the Level 2 responsivity, the lamp measurements collected in 2015 with Brewer \#107 are used and each phase in the process is described in the following sections. The phases are illustrated in Fig. 8.

\subsubsection{Phase 1}

The primary standard lamps D01 and D05 were recalibrated in NSL on 19 May 2015. They were measured by Brewer \#107 in the on-site darkroom in Jokioinen on 23 June 2015 (Julian date 174/15). D01 and D05 have both proved very stable in time as may also be seen in Figs. 4 and 5. The determination of the Level 2 responsivity is decided to be based on these two primary standard lamps. The responsivity for the instrument for day $174 / 15$ is defined as the average of the responsivity obtained from the measured count rates and newly certified irradiances of D01 and D05. This will serve 


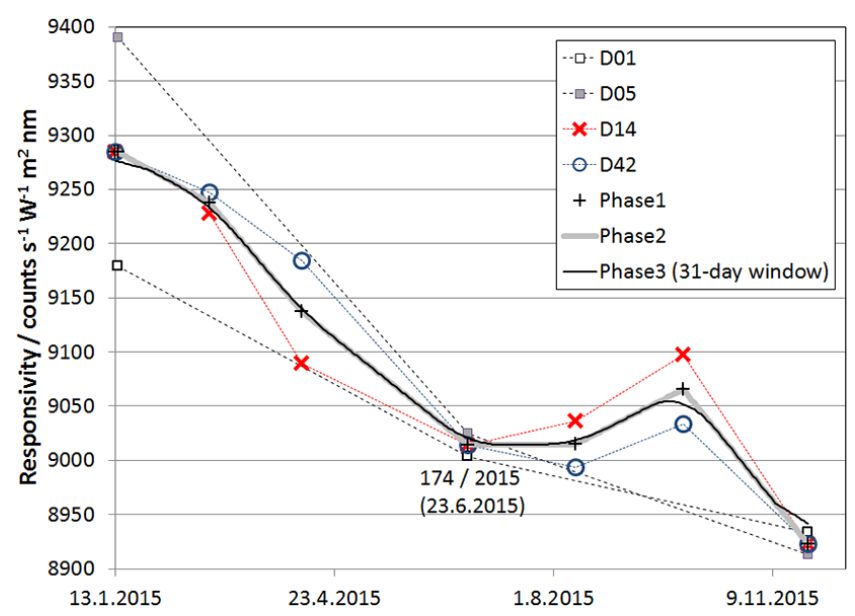

Figure 8. Demonstration of the phases in the determination of the final responsivity of type Level 2 used for post-processing of solar spectral UV irradiance measured by Brewer \#107 spectrophotometer. The dashed lines are plotted to guide the eye.

as an anchor point for the daily responsivity to be determined for the selected time period.

The irradiance scale may now be transferred to all the lamps measured on-site on day 174/15 using Eq. (1). This is done here for the frequently used, but very stable and hence trusted, working standard lamps D14 and D42. In practice, certificates for the irradiance of lamps D14 and D42 on day $174 / 15$ are produced, using the responsivity determined on the basis of the measurements of lamps D01 and D05. The responsivity of the instrument is further calculated on the basis of the count rates obtained from the measurements of D14 and D42 on day 174/15. The procedure positions the responsivity determined on the basis of the lamps D14 and D42 both in the middle of those obtained on the basis of the lamps D01 and D05 on day 174/15.

During 2015, lamps D01 and D05 have been measured in the on-site laboratory also on 14 January $2015(014 / 15)$ and 25 November $2015(329 / 15)$. Irradiance of the lamps on those days is assumed the same as on day $174 / 15$, i.e. the same as the readings in the certificate given by NSL dated 19 May 2015. The working standard lamps D14 and D42 were also measured on days $013 / 15$ and $329 / 15$. They can be therefore calibrated against the average of D01 and D05 on these two additional measurement days in the same way as on day $174 / 15$. Again, the transfer of calibration positions the responsivities determined for lamps D14 and D42 in the middle of those determined for the primary standard lamps D01 and D05.

The working standard lamps D14 and D42 have been measured by Brewer \#107 in the on-site laboratory on days $056 / 15,098 / 15,223 / 15$, and $272 / 15$ in addition to the days $013 / 15,174 / 15$, and $329 / 15$. These measurements provide four additional points in time to be used in the determination of the responsivity time series. For the time period 174/15-
$329 / 15$ this is fortunate because there is a short-term change in the responsivity of the instrument detected by the lamps D14 and D42. Measurements with the $50 \mathrm{~W}$ lamps during the same time period indicate the same change, so it may be concluded that the change is real. The irradiances for the lamps D14 and D42 are calculated by linear interpolation between the irradiances fixed onto the scale provided by the lamps D01 and D05 for days 013/15, 174/15, and 329/15. The corresponding responsivities for the lamps D14 and D42 are calculated from the measured count rates and the assumed irradiance. Finally, an average of the responsivities determined for the lamps D14 and D42 is calculated, marked as black crosses in Fig. 8.

\subsubsection{Phase 2}

The discrete responsivity derived as an average of the lamps D14 and D42, calibrated against the average of the primary standard lamps D01 and D05, are next used to derive a time series of responsivity. The discrete points are connected with linear interpolation in time, resulting in a time series in the form of a polyline. The obtained time series, giving daily responsivity for Brewer \#107, could already be used as such in post-processing of solar UV irradiance data. The time series is plotted with a thick grey line in Fig. 8.

\subsubsection{Phase 3}

The polyline-shaped time series of responsivity derived in Phase 2 contain sharp turning points. In most cases it may be assumed that in reality the changes are not that sudden in the responsivity of the instrument. The time series may therefore be filtered using a moving average with a window of suitable width. This is done here using a window of width of 31 days. The selection of the width depends on how small variations in the time series are to be retained and in which extent the sharp turns in the time series are to be smoothed away. The resulting time series is plotted with a thin black line in Fig. 8. This is considered a Level 2 responsivity time series that could be used for the post-processing of the solar spectral UV irradiance measurements collected during the year 2015 .

The demonstration presented here is confined to the lamp measurement data collected during 2015. The responses derived on the basis of the measurements of the lamps D01 and D05 in the on-site laboratory on day 014/15 appear to be fairly far from each other. It is possible that irradiance of either one of the lamps has changed as compared to that determined by NSL on day $174 / 15$. Alternatively, the count rates recorded during the scan of either one of the lamps may be faulty as a result of instabilities in the lamp voltage, for instance. In practice, the previous recalibrations of the primary standard lamps are also taken into account, as well as the Level 2 responsivity derived in the previous post-processing event. This ensures that the reference points in the time se- 


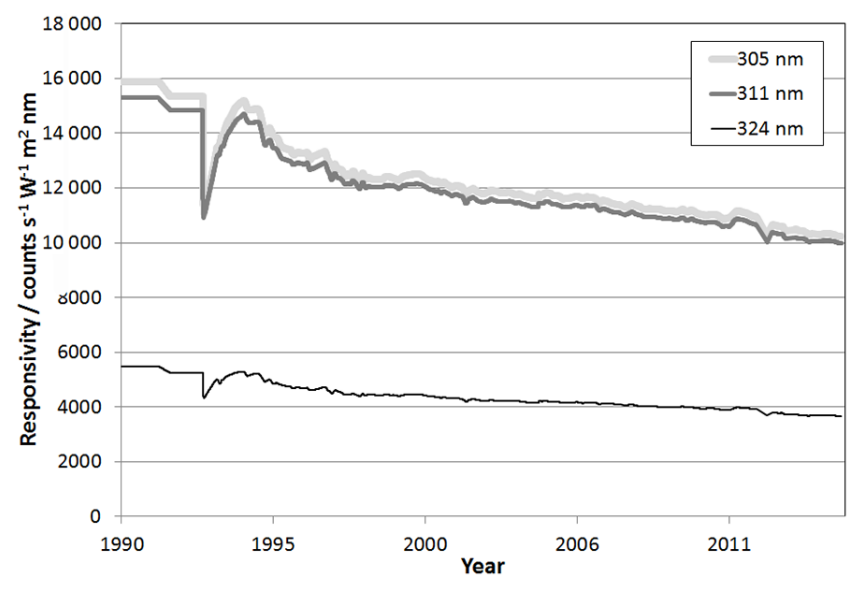

Figure 9. Level 2 responsivity of Brewer \#037 at different wavelengths for the time period 1 January 1990-9 December 2015 used for post-processing of solar UV irradiance spectra.

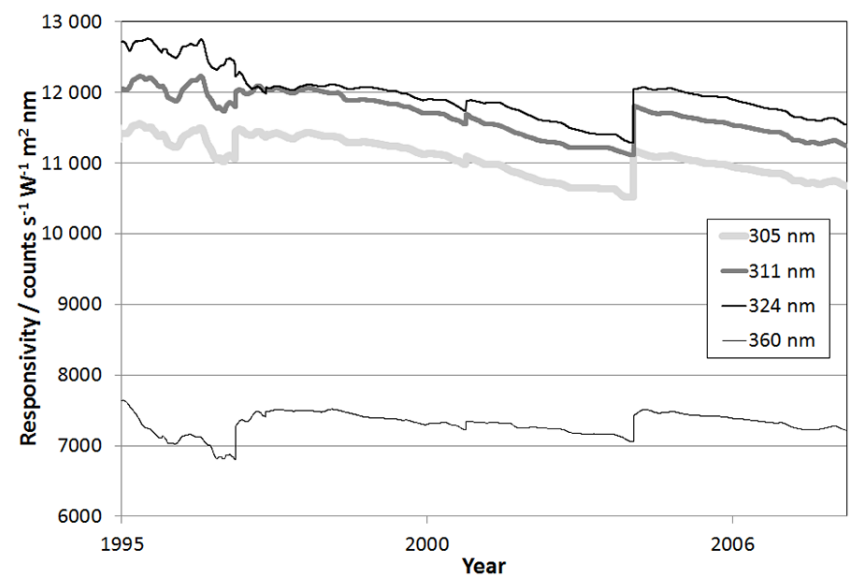

Figure 10. Level 2 responsivity of Brewer \#107 at different wavelengths for the time period 20 March 1995-7 April 2008 used for post-processing of solar UV irradiance spectra.

ries of the responsivity are fixed onto correctly chosen trusted lamps.

The Level 2 responsivity time series used in postprocessing of the UV irradiance spectra measured by Brewer \#037 and \#107 are shown in Figs. 9 and 10 respectively. The time series for Brewer \#037 is complete and extends over the whole operational lifetime of the instrument. For Brewer \#107, work is under way to re-evaluate all the lamp scans taken since the beginning of 2008 , to extend the existing Level 2 responsivity time series until the end of 2015.

\section{Discussion}

The lamp measurement data collected over the operational years of Brewer \#037 and Brewer \#107 spectrophotometers include altogether 1931 and 2012 scans respectively.
The data allow retrospective examination of the changes that occurred both in the lamps themselves and in the responsivity of the instruments. Looking into the raw counts obtained from the lamp measurements of Brewer \#037 and Brewer \#107 already revealed long-term declination and abrupt jumps in the responsivity. The features observed in the raw counts may be considered truly attributable to changes in the responsivity as all the lamps indicate the same behaviour, independent of the frequency at which they are burned. However, separation of the ageing of the lamps from the changes in the responsivity would be meaningful and should be possible by employing a linear mixed model, for instance.

Brewer \#037 and Brewer \#107 have both been frequently compared with the portable EU reference spectroradiometer QASUME, Quality Assurance of Spectral Ultraviolet Measurements in Europe (Bais et al., 2003). The comparisons provide external and additional evidence of the calibration stability of the instruments. During the QASUME site visits in 2002-2003, the ratio of the irradiance measured by Brewer \#037 (Brewer \#107) was found to be 1.05 in UVB and 1.03 in UVA (1.03 in UVB and 1.02 in UVA) (Gröbner et al., 2006). In addition, the site visits to Jokioinen in 2002 and 2003 proved that the performance of Brewer \#107 was stable between the 2 consecutive years (Gröbner et al., 2005).

Regular recalibrations of the primary standard lamps enable identification of changes in the radiative output of the lamps. The temporal development of the primary standard lamps of Brewer \#037 and Brewer \#107 showed ageing in general. Individual differences between the lamps obviously exist in regard to their stability. The primary standard lamps used by Brewer \#107 are burned more sparingly than the ones used by Brewer \#037. This might be a feasible strategy when aiming at minimizing the ageing of the lamps. Following the temporal development of the radiative output of all the lamps is worthwhile since it also enables identification of the most stable lamps, which would serve well as frequently scanned working standard lamps.

The determination of the responsivity for both near realtime processing and post-processing of solar spectral UV irradiance includes phases where the operator has to make a choice between several alternatives. Up to the discretion of the operator are, for instance, which primary standard lamp(s) is to be used as the basis of the determination of the responsivity of the instrument, which secondary/working standard lamps are to be used when a sudden change in the responsivity is obvious in between the recalibrations of the primary standard lamp and the Level 1 responsivity for the near real-time processing needs to be updated; which lamps should be used when determining the Level 2 responsivity for the post-processing of solar spectral UV irradiance data, how small variations in the responsivity would be meaningful to be retained both in Level 1 and Level 2 responsivity, how heavily the Level 2 responsivity time series should be smoothed, etc. Quantified criteria would be very helpful for the operator making the decisions. 
The strategy of using multiple primary standard lamps that are regularly and rotationally recalibrated by NSL and multiple secondary/working standard lamps that are frequently measured in the on-site laboratory produces a lot of data that have to be regularly and carefully examined. They are, however, a prerequisite for identification of short-term changes in the responsivity of the spectrophotometer. The large number of data that have to be processed with many scripts through many intermediate steps call for carefully designed data management. This is essential in an attempt to ensure coherence in the continuance of the data processing.

\section{Conclusions}

Two Brewer spectrophotometers have been used to monitor solar spectral UV irradiance at Sodankylä and Jokioinen, Finland, for about 20 years according to the guidelines defined by GAW/WMO. The on-site measurements of 50 and $1000 \mathrm{~W}$ lamps used for calibration and stability checks have produced a data set containing about 2000 scans for both instruments. The data enable retrospective examination of the temporal development of the response of the spectrometers. Both instruments show long-term decrease in their responsivity. In addition, abrupt changes as large as $-25 \%$ at $311 \mathrm{~nm}$ in the responsivity of Brewer \#107 have occurred. The primary standard lamps regularly recalibrated by the National Standards Laboratory appear to age at a rate of $0.05-0.6 \%$ per burn. The finding encourages sparing use of the primary standard lamps in the on-site laboratories. Examination of the responsivity time series based on three primary lamps revealed lags of up to 12 months in the detection of the abrupt changes. The lags were avoided and the sudden changes detected in due time by frequent measurements of the working standard lamps. This demonstrates the need for frequent measurements of working standard lamps.

The large number of data accumulating from the lamp measurements and the multi-phase processing of the data call for carefully designed data management. Future work should also include determination of quantified criteria to assist the operator in making decisions on the various phases of the determination of the responsivity. This requires further research on the data, including experimentation with the different choices and evaluation of the consequences of each choice.

\section{Data availability}

The research data underlying this study are available from the corresponding author on request.

Acknowledgements. The authors gratefully acknowledge the personnel in the Arctic Research Center in Sodankylä and at Jokioinen Observatory for taking care of the daily maintenance, the on-site quality control, and the lamp measurements made with Brewer spectrophotometers \#037 and \#107.

Edited by: M. Zribi

Reviewed by: two anonymous referees

\section{References}

Bais, A., Zerefos, C., and McElroy, C: Solar UVB measurements with the double- and single-monochromator Brewer Ozone Spectrophotometers, Geophys. Res. Lett., 23, 833-836, 1996.

Bais, A., Blumthaler, M., Gröbner, J., Seckmeyer, G., Webb, A. R., Görts, P., Koskela, T., Rembges, D., Kazadzis, S., Schreder, J., Cotton, P., Kelly, P., Kouremeti, N., Rikkonen, K., Studemund, H., Tax, R., and Wuttke, S.: Quality assurance of spectral ultraviolet measurements in Europe through the development of a transportable unit (QASUME), in: Ultraviolet Ground- and SpaceBased Measurements, Models, and Effects II, edited by: Gao, W., Herman, J. R., Shi, G., Shibasoki, K., and Slusser, J. R., SPIE, 4896, 232-238, 2003.

Brewer, A. W.: A replacement for the Dobson spectrophotometer?, Pure Appl. Geophys., 106-108, 919-927, 1973.

Damiani, A., De Simone, S. Rafanelli, C., Cordero, R., and Laurenza, M.: Three years of ground-based total ozone measurements in the Arctic: Comparison with OMI, GOME and SCIAMACHY satellite data, Remote Sens. Environ., 127, 162-180, 2012.

Eleftheratos, K., Kazadzis, S., Zerefos, C. S., Tourpali, K., Meleti, C., Balis, D., Zyrichidou, I., Lakkala, K., Feister, U., Koskela, T., Heikkilä, A., and Karhu, J. M.: Ozone and Spectroradiometric UV Changes in the Past 20 Years over High Latitudes, Atmos. Ocean., 53, 117-125, doi:10.1080/07055900.2014.919897, 2014.

Garane, K., Bais, A. F., Kazadzis, S., Kazantzidis, A., and Meleti, C.: Monitoring of UV spectral irradiance at Thessaloniki (19902005): data re-evaluation and quality control, Ann. Geophys., 24, 3215-3228, doi:10.5194/angeo-24-3215-2006, 2006.

Gardiner, B. G.: Spectroradiometer calibration methods and techniques, in: Solar Ultraviolet Radiation, edited by: Zerefos, C. S. and Bais, A. F., NATO-ASI Series, 52, Springer, Heidelberg, Berlin, New York, 119-132, 1997.

Gröbner, J., Schreder, J., Kazadzis, S., Bais, A. F., Blumthaler, M., Görts, P., Tax, R., Koskela, T., Seckmeyer, G., and Webb, A. R.: Traveling reference spectroradiometer for routine quality assurance of spectral solar ultraviolet irradiance measurements, Appl. Opt., 44, 5321-5331, 2005.

Gröbner, J., Blumthaler, M., Kazadzis, S., Bais, A., Webb, A., Schreder, J., Seckmeyer, G., and Rembges, D.: Quality assurance of spectral solar UV measurements: results from $25 \mathrm{UV}$ monitoring sites in Europe, 2002 to 2004, Metrologia, 43, S66-S71, 2006,.

Ialongo, I., Casale, G. R., and Siani, A. M.: Comparison of total ozone and erythemal UV data from OMI with ground-based measurements at Rome station, Atmos. Chem. Phys., 8, 3283-3289, doi:10.5194/acp-8-3283-2008, 2008.

Kazadzis, S., Bais, A., Kouremeti, N., Gerasopoulos, N., Garane, K., Blumthaler, M., Schallhart, B., and Cede, A.: Direct spectral measurements with a Brewer spectroradiometer: Absolute cali- 
bration and aerosol optical depth retrieval, Appl. Opt., 44, 1681$1690,2005$.

Kübarsepp, T., Kärhä, P., Manoocheri, F., Nevas, S., Ylianttila, L., and Ikonen, E.: Spectral irradiance measurements of tungsten lamps with filter radiometers in the spectral range $290 \mathrm{~nm}$ to $900 \mathrm{~nm}$, Metrologia, 37, 305-312, 2000.

Lakkala, K., Arola, A., Heikkilä, A., Kaurola, J., Koskela, T., Kyrö, E., Lindfors, A., Meinander, O., Tanskanen, A., Gröbner, J., and Hülsen, G.: Quality assurance of the Brewer spectral UV measurements in Finland, Atmos. Chem. Phys., 8, 3369-3383, doi:10.5194/acp-8-3369-2008, 2008.

Lam, K. S., Ding, A., Chan, L., Wang, T., and Wang, T.: Groundbased measurements of total ozone and UV radiation by the Brewer spectrophotometer \#115 at Hong Kong, Atmos. Environ., 36, 2003-2012, 2002.

Mäkelä, J. S., Lakkala, K., Koskela, T., Karppinen, T., Karhu, J. M., Savastiouk, V., Suokanerva, H., Kaurola, J., Arola, A., Lindfors, A. V., Meinander, O., de Leeuw, G., and Heikkilä, A.: Data flow of spectral UV measurements at Sodankylä and Jokioinen, Geosci. Instrum. Method. Data Syst., 5, 193-203, doi:10.5194/gi-5-193-2016, 2016.

Sabburg, J., Rives, J. E., Meltzer, R. S., Taylor, T., Schmalzle, G., Zheng, S., Huang, N., Wilson, A., and Udelhofen, P. M.: Comparisons of corrected daily integrated erythemal UVR data from the U.S. EPA/UGA network of Brewer spectroradiometers with model and TOMS-inferred data, J. Geophys. Res., 107, 4676, doi:10.1029/2001JD001565, 2001.

Schneider, M., Redondas, A., Hase, F., Guirado, C., Blumenstock, T., and Cuevas, E.: Comparison of ground-based Brewer and FTIR total column $\mathrm{O}_{3}$ monitoring techniques, Atmos. Chem. Phys., 8, 5535-5550, doi:10.5194/acp-8-5535-2008, 2008.
Seckmeyer, G., Bais, A., Bernhard, G., Blumthaler, M., Booth, C. R., Disterhoft, P., Eriksen, P., McKenzie, R. L., Miyauchi, M., and Roy, C.: Instruments to measure solar ultraviolet radiation, Part 1: Spectral instruments, Global Atmosphere Watch Report No. 125, World Meteorological Organization (WMO), Geneva, Switzerland, 31 pp., 2001.

Simic, S., Weihs, P., Vacek, A., Kromp-Kolb, H., and Fitzka, M.: Spectral UV measurements in Austria from 1994 to 2006: investigations of short- and long-term changes, Atmos. Chem. Phys., 8, 7033-7043, doi:10.5194/acp-8-7033-2008, 2008.

Walker, J. H., Saunders, R. D., Jackson, J., and Mielenz, K. D.: Results of a CCPR intercomparison of spectral irradiance measurements by national laboratories, J. Res. Natl. Inst. Stand. Technol., 96, 647-668, 1991.

Webb, A. R., Gardiner, B. G., Martin, T. J., Leszczynski, K., Metzdorf, J., and Mohnen, V. A.: Guidelines for site quality control of UV monitoring, Global Atmosphere Watch (GAW) Report No. 126, TD No. 884, World Meteorological Organization (WMO), Geneva, Switzerland, 39 pp., 1998.

Webb, A. R., Gardiner, B. G., Leszczynski, K., Mohnen, V., Johnston, P., Harrison, N., and Bigelow, D.: Quality Assurance in Monitoring Solar Ultraviolet Radiation: the State of the Art, Global Atmosphere Watch (GAW) Report No. 146, TD No. 1180, World Meteorological Organization (WMO), Geneva, Switzerland, 45 pp., 2003. 